\title{
PIRANDELLO E O REALISMO DA LINGUAGEM
}

Wilma K. B. de Souza

Luigi Pirandello, que nasceu na última metade do século XIX (1867), e morreu na primeira metade do século XX (1936), viveu a passagem e o encontro de duas etapas da era moderna, e presenciou, assim, o choque mais importante e mais decisivo para a atualidade, de onde saem as raízes de sua poesia, historicamente explicadas como uma clara tomada de consciência da crise européia entre os dois séculos.

As certezas da burguesia italiana, silenciadas na revolução liberal, dissolvem-se e provocam um clima de total instabilidade na sociedade de então. Um vazio profundo e não preenchido ecoa, dolorosamente, na consciência dos homens, que se projetam nos herois de Pirandello; mas estes não são o super-homem de Nietzsche, de Wagner ou de Ibsen; são as múltiplas formas do anti-heroi que, às vezes, se torna um vencedor; é o fugitivo Mattia Pascal, à procura da identidade na liberdade, na evasão, recolhido, finalmente, no mundo da sua memória e que, diariamente, deposita flores em seu próprio túmulo; é o mordomo Pinzone contra Liolá, o rústico siciliano, e, ainda muitos outros, que lutam pela reconquista da realidade.

O grito existencial, com que se exprime esses personagens, angustia e, algumas vezes, nos faz rir, para não deplorar esse mundo louco em que vivemos. A "lúcida loucura" de Enrico IV é um modelo da consciência inquieta de uma Europa devassada pela psicalálise de Freud e dos modernos caçadores de almas.

De tudo isso Pirandello participou, e foi membro atuante - daí a sua grande atualidade, que, entretanto, lhe custou bem caro, pois, se conheceu, ainda em vida, o sucesso e a glória universais (recebeu o Prêmio Nobel em 1934) e foi consagrado pelas multidões, que o aplaudiram no mundo inteiro, não foi menor alvo de críticas acerbas no ambiente cultural e literário da Itália, as quais the contestaram a

Língua e Literatura, (14), 1985. 
poeticidade e o valor artístico, atribuindo-lhe, até, a autoria de uma filosofia "senza capo né coda"

A oposição à sua obra monumental, menos pela qualidade do que pela quantidade, encontrou uma agravante na atuação política, que desempenhou durante o fascismo em sua terra, não tanto porque fosse um político engajado na ditadura de Mussolini, mas, mais, porque, tendo recebido do governo um lugar no primeiro grupo de acadêmicos na então recém-criada Accademia d'Italia (desaparecida depois da libertação), requereu a entrada no Partido Fascista, em 1924, logo depois do delito Matteotti, o que causou grande reação e descontentamento às oposições. Tendo sido sempre considerado um "apolítico" a reprovação de tais atos recaiu no julgamento e na condenação de suas obras, transformado, logo, num "escritor fascista" Entretanto, como bom siciliano, nunca deixou de denunciar, juntando a sua às vozes de Giovanni Verga e de Luigi Capuana, o abandono e a exploração das populações meridionais. Talvez, à desilusão advinda do "Risorgimento" uniu o seu desprezo pelos políticos liberais, de grandes idéias da propalada renovação social, que iludiam a burguesia ainda feliz pela "unificação italiana"

O italiano, já disse alguém, é, antes de tudo, um homem da sua cidade, da sua província e, depois, italiano.

Alguns intelectuais da Itália do começo do século, a despeito de toda a resistência que opunham àquela "atmosfera espiritual" como chamou Francesco Flora ao Futurismo, faziam restrições ao passado, tendiam a proclamar a irreligiosidade da vida e o empenho numa grande fé no futuro. Este, em contrapartida, estava longe de proporcionar-lhes aquilo em que os futuristas, em seus manifestos e em sua arte menor, propunham: construir um mundo novo com "a geometria rígida das largas pontes de metal e as fábricas expelindo trens ondulantes de fumaça; abolir, em toda parte, as curvas lânguidas da velha arquitetura, reconstrui-lo sobre as cinzas das gôndolas, esses vôos para tolos"

Outros espíritos da mesma época são assaltados por um mundo de indecisão e de dúvida contínua: Papini, um dos escritores mais lidos oscilavam entre a fé e a razão, entre o bem e o mal, atitudes vasadas num estilo autobiográfico, bem ao gosto da moda. Alfredo Panzini, o ídolo da burguesia, vagava entre a poesia e a prosa atípicas e descaracterizadas, que nunciavam a transição da linguagem do século.

Pirandello é o terceiro representante dessa época, talvez, o maior e o mais complexo. Porisso, ao tentar enquadrá-lo em qualquer 
"ismo" que viu surgir no séc. XX, enfrentamos com perplexidade, a sua figura poliédrica e a sua não menos discutida arte.

Aproximá-lo do Futurismo, apenas longinquamente, pois sabemos que 0 autor siciliano se afasta, decididamente, daquela mentação preconizada por Marinetti, na qual o amor é velocidade, a destruição do passado e a robotização do homem seria os ideais supremos de um "admirável mundo novo" Mas o nosso Autor, ao contrário, em longos períodos onde desce a minúcias de um quase descritivismo pscológico, chega à verificação de uma "loucura" de um "delito" e de uma "insensatez" como resultantes de "todo este fragoroso e vertiginoso mecanismo da vida", que "só pode produzir estupidez" "Quaderni di Serafino Gubbio operatore" (nossa tradução) (1).

Ele sempre foi um homem que suscitou contrastes: é conhecida a orça com que participou da vida teatral contemporânea, dirigindo, plasmando, construindo e reconstruindo seus personagens.

A relação autor-personagens é tão fortemente dialética que, em seus "Saggi" como em outros escritores sobre arte, "Arte e Scienza" (2), deixa idicado um problema de muita relevância. São suas palavres:

"Não é o drama que faz as pessoas; mas, estas, o drama. $\mathrm{E}$, antes de qualquer outra coisa, é preciso que existam as pessoas vivas, livres e operantes. Com elas e nelas nascerá a idéia do drama, o primeiro germe onde estarão presos $o$ destino $e$ a forma; porque em todo o germe já freme o ser vivo, assim como na bolota está o carvalho com todos os seus ramos" (grifos e trad. nossos).

A obra de arte não prescinde das "persone" mas prende a elas a sua fortuna e a sua forma, daí constituirem-se numa unidade inequiívoca com a linguagem do autor.

Eis um dos seu temas permanentes: a relação negativa entre forma e realidade, tomando-se por "forma" a perda da substância real, dentro das normas do passado, com as quais o romance moderno rompeu definitivamente. E Pirandello está entre esses modernos.

Daí, também, a perenidade dos personagens, que vivem "por sua conta", que marcam a própria trajetória ao estilo e aos modos de dizer do seu criador

(1) - Quaderni di Serafino Gubbio, operatore e Novelle per un anno, Milano, A. Mondadori, 1938. 2 vols.

(2) - Todos os trechos dos Saggi e Arte e Scienza estāo em L'Estetica di Pirandello de Claudio Vicentini, Milano, U Mursia, 1970. 
Essa coexistência, essa verdadeira simbiose, já era, desde os primeiros escritos de juventude, algo da consciência que o perseguiu por toda a vida, muito antes dos "seis personagens à procura de um autor" Numa carta de 1904, assim escrevia ele: (3)

“. .se os cuidados materiais e os empenhos sociais não me distraíssem, creio que ficaria desde a manhã até à noite aqui, em meu escritório, a serviço dos personagens das minhas histórias, os quais se atropelam ao meu redor" E de tal forma o atropelam, perseguem-no, até, que se transformam em tipos, que aparecem em obras diferentes, povoando o mundo e a estrutura profunda da realidade implantada na sua arte.

Luigi Capuna, seu professor de estética, inspirou-lhe uma concordância perfeita no plano das idéias, como podemos deduzir do seu escrito sobre Coscienze. "No prefácio amargamente arguto do seu último volume de contos, Coscienze, Luigi Capuana quis reafirmar a sua antiga conviç̧ão de que o conto deve ser, unicamente, a criação de caracteres, de personagens, que vivam, na obra de arte como na realidade, por sua conta ( .) Tal conviç̧ão encerra um critério de arte e uma norma que não se referem, propriamente, ao conto, somente, mas a toda a obra literária que não queira ser um fútil jogo ou um tolo exercício de estilo"

A sua consciência poética, bastante fermentada por elementos verísticos e de influência naturalista, leva-o a desenvolver um estilo muito original.

O percurso que os seus contos e os seus romances têm de realizar até a manutenção das suas obras de teatro é pontilhado de experiências no plano teórico, como bem o demonstram os seus ensaios e a obra crítica que exercitou, sobre os escritores, clássicos e seus contemporâneos, de que se ocupou. E na maior parte das reflexões sobre assuntos polêmicos que fez, vai revelando como se põe em relação explícita com as suas criaturas:

"É meu velho hábito dar ouvidos, todos os domingos de manhã, aos personagens dos meus futuros contos. Cinco horas, das oito às treze horas" Assim, em 1911, ele escreve em "La tragedia di un personaggio."

A essa relação acrescenta mais um dado: "a vida material cheia de vis dificuldades que impedem, deformam e tornam mísera a existência aprisiona ao quotidiano e o destina ao tédio e à anulação de si (. . )" - "ter o privilégio de ter nascido personagem" eis a fórmu-

(3) — ibidem, p. 163 e sgs. 
la com que define essa nova realidade" Quem nasce personagem, quem tem a ventura de nascer personagem vivo pode zombar até da morte. Não morre mais! Morrerá o homem, o escritor, instrumento natural da criação; a criatura não morre mais!. talvez, sejamos menos reais mas mais verdadeiros! (La tragedia di un personaggio). (4)

Essa "verdade", que copia a imagem interior é a mesma que copia a verdade exterior, como disse um crítico, a respeito do realismo moderno (Arrigucci Jr ). E a fantasia como atividade criadora, que intervém na natureza, e prossegue no seu ofício de criação.

E, também, a imortalidade, em termos de realismo fantástico, que Pirandello anuncia.

A condição humana se eleva à categoria perene, quando nasce da arte, adquire a segunda articulação, feita de puro subjetivismo, concretizada como intenção pessoal, como vontade própria de viver $\mathrm{E}$, para Pirandello, ela significa a sujeição total àquela "servetta" "sveltisima, dispettosa e beffarda" que o acompanha, tal como nos declara no prefácio a "Sei personaggi.

E a fantasia que "se diverte em levar-lhe à casa, para que ele povoe o mundo de seus contos, romances e peças de teatro, "a gente mais descontente do mundo" homens, mulheres, crianças envolvidos em casos estranhos, de que não encontram maneira de sair, contrariados em seus desígnos, frustados nas suas esperanças, e com os quais é, freqüentemente "muito perigoso ter de tratar" Eis-nos, de novo, diante da imensa galeria de andrajos humanos tão reais quanto fantásticos.

"O mistério da criação artística é o próprio mistério do nascimento natural" $\mathrm{O}$ realismo de Pirandello, convergindo do subjetivismo do autor para a objetivação do personagem explica-se, ao nível dos fenômenos, na unidade sujeito-objeto, direcionada para o universal. Não é no universal, ainda, que se capta a realidade: essa clivagem se estabelece na consciência do autor, que a refrata e vivencia a verossimilhança do personagem. Ele conquista horizontes puramente imaginários, que novamente se insinuam no mundo real: este se torna fantástico, pois seu apoio é o mistério indecifrável.

"Mas que autor poderá sondar o mistério" desses partos fantástico? pergunta-nos, indiretamente, Pirandello.

Hoje, mais de cem naos depois, responde-lhe Jorge Luiz Borges:

(4) - "La tragedia di un personaggio" in Novelle per un anno, Firenze, Ed. Bemporad, 1922, vol. LV 
"No bojo do real cabe o fantástico"

O dramaturgo siciliano insiste em afirmar a superioridade dos filhos da arte em relação aos produtos da "volúvel existência cotidiana" - estes, pobres entes, vivem, deixam-se viver; aqueles "querem viver"

Entretanto, o autor declara que não tem o simples "gosto" de representá-los; recusa-se a inseri-los na história, mas atribui-lhes um particular "sentido de vida", como se para atingir o valor universal precisassem existir fora da história; mas na história, ou mais exatamente, é na pré-história do pensamento, na intuição artística, tão propalada por Crose, que Pirandello historicisa a sua poétca.

Para Capuana e para Goethe, a espontaneidade da criação artística deveria adequar-se, rigorosamente, ao "sujeito" - "eu" e "matéria" revelados ambos no estilo e na linguagem do escritor.

Para o autor agrigentino, "fundir a subjetiva individualidade de um caráter com a sua especificidade no drama, encontrar a palavra que, mesmo respondendo a um ato imediato a situação na cena, exprima a totalidade do ser da pessoa que a profere: eis a suma dificuldade que o artista deve superar" (grifos nossos).

A esta poética da palavra dramática corresponde todo o processo de transfiguração artística do discurso pirandelliano.

Confirmam-no as interrogações de Gramsci (5), acerca do caráter fantástico, da multiplicidade e da diversidade das posiçōes conquistadas nesse teatro. Pirandello afirma a natureza filosófica da sua impostação artística; Gramsci confirma que o escritor siciliano reflete pontos de vista existentes na própria vida e na cultura da época, e, mesmo, na cultura "de baixo nível" popular, folclórica.

De fato, o público italiano sempre acolheu com uma grande curiosidade e com notável interesse essa arte de "personagens sem autor" que viviam "por conta própria" e, que, além dos palcos ganhou as ruas e se transformou em fala popular, à qual as companhias teatrais recorriam nos momentos de crise.

"Odeio a arte simbólica, em que a representação perde todo o movimento espontâneo para se tornar máquina, alegoria; (.) A necessidade espiritual de que falo só pode satisfazer-se, e para um fim superior de ironia, de um símbolo alegórico que

(5) - Gramsci, A., Cultura e vida nacional, Brasil, Civilização Brasileira 1968 . 
parta de um conceito para fazer-se imagem...; essa, que deve permanecer livre em toda a sua expressão procura um sentido que lhe dê valor"

Esse sentido, Pirandello encontrou na existência própria daquelas "criaturas do seu espírito" da vida que ele já não podia negar-lhes.

Mas toda a teoria exposta nos "Sei personaggi. " constituem parte das reflexões diante do problema de como a arte possa realizar e revelar a estrutura profunda da realidade, e, não reduzíla à pura expressão do autor. Em outras palavras, é a tentativa de colher na arte a transformação de indivíduos em pessoas, distantes e diversas do seu criador.

Outro aspecto dessa teoria revela-se na visão de poesia e de trabalho poético inserido nos "Saggi" sobre o humorismo:

"Um poeta não pode, não crendo na realidade da própria criação, representá-la como se acreditasse nela, isto é, mostrar, verdadeiramente, consciência da realidade dela; pode representar como verdadeiro um mundo seu, fantástico, de sonho, regulado por leis próprias e segundo essas leis, perfeitamente lógico e coerente.. A arte é criação e não conhecimento; mas a criação de arte não é ex nihilo; tem necessidade do conhecimento, tem necessidade de que, em primeiro lugar, a coisa seja conhecida pela abstração, conhecida em si mesma, e na palavra que é o seu símbolo e a representação geral"

Essa palavra tomada como símbolo da inteligência das coisas está muito próxima daquela a que se referiu, mais radicalmente, Thomas Mann, quando disse que "um romance tem de ser mais que um romance, talvez um ensaio, talvez um tratado, talvez um sistema filosófico"! (grifos nossos).

Em contrapartida, o conceito de Pirandello de que "a língua, estreitamente ligada à vida, cujo uso espontâneo, corresponde a um "sentimento natural" fez com que muitos críticos o considerassem um escritor dialetal. Na verdade, o nosso autor estava consciente de que enquanto a língua é um sistema de símbolos, que se refere à estrutura objetiva das representações, o estilo é a animação subjetiva da palavra; o uso vivo e constante da língua é feito pelo povo que a fala. Neste falar o escritor recupera o sentido da criação, a atividade fantástica.

Pirandello escreveu muitos contos e peças de teatro em dialeto siciliano: personagens populares, vivendo dramas da província da 
"Ilha de fogo" como a chamou Dante. Realizou-a com a plena consciência de algumas razões que o levaram a usar o dialeto como meio de comunicação: a maior vivacidade da língua dialetal para a expressão da espontaneidade nativista, primeira condição da arte; a ligação íntima dos sentimentos e das imagens subjetivas à terra de que ele se fez intérprete; e, para nós mais complexa, a impossibilidade de representação da realidade regional fora dos seus limites naturais.

"Ora, ao que parece, no teatro dialetal, o pirandellismo é justificado por modos de pensar "historicamente" populares e popularescos, dialetais ( ) trata-se de populares sicilianos, que pensam e agem daquele modo, precisamente, porque são populares e sicilianos." (6)

Gramsci acrescenta a esse ideário do poeta siciliano:

"Liolá", que muitos críticos consideram a sua melhor peça escrita em dialeto, está impregnada de humor levemente satírico. $E$ interessante comparti-la à linguagem das peças de Capuana e de Nino Martoglio: quase os mesmos tipos humanos passam por essas obras - o velho mísero e calculista, como o velho Pantaleão, apaixona-se por uma jovem e é enganado por seu cobiçado amor; o bom e o mau irmão, ambos, em contraste, amando a mesma moça; o D. João rústico, que canta, enquanto trabalha, e aceita o amor de todas as moças da região, como se fossem todas suas. Capuana e Martoglio são estritamente fiéis aos costumes regionais; Pirandello, nessa peça é o humorista que, enquanto sorri, observa o homem. Guido Ruberti analisa, assim, o seu estilo:

"A característica dessa peça não é francamente cômica ou essencialmente dramática, nem alegre nem triste, mas sorridente e sombria ao mesmo tempo, simples e envolvente, superficial e profunda"

$\mathrm{Na}$ verdade em "Liolá" renuncia ao "dialeto burguês" aquela híbrida linguagem entre a língua e o dialeto" que, com um pouco de deselegância e um pouquinho de arredondamento se transforma na língua italiana falada comumente $e$, talvez, não só fadada pelos incultos, na Itália. "Liolá", comédia campestre, foi recitada por expressa vontade do autor, assim como foi escrita, em "pretto vernacolo" tal como convinha aos personagens, todos camponeses do cam. po agrigentino" (Prefácio a "Liolá")

Ao interpretar, assim, o uso da língua, valoriza o lirismo da expressão do cotidiano e subordina o realismo prosaico ao meio em

(6) - ibidem, p. 51 e sgs.

(7) - Ruberti, G., Il Teatro contemporaneo in Europa, Bologna, 1920 
que se exprime, isto é, a linguagem muda de estado; ela não é mais o instrumento do real mas se transforma na sua própria natureza: é o realismo da linguagem.

Não obstante, é preciso desvincular a obra restante de Pirandello de uma perspectiva restritamente regional, para colocá-la mais vastamente num horizonte universal da literatura européia.

A prosa narrativa tende, intrinsecamente, ao desenvolvimento dramático, pois vai apresentando uma "descontinuidade expressionista" como a chama Leone de Castris (8) cujo espaço limítrofe é, a nosso ver, o romance Uno, nessuno, centomila.

Ao instalar, nesse romance a desmedida da personalidade, que se decompõe entre o existir e o ser, desintegrando-lhe a unidade, segundo as conveniências da ilusão, diluindo o "sujeito" em tantas quantas são as possibilidades do objeto, como que refletido, infinitamente ao espelho, o autor não se apressa em dar um nome ao protagonista. Este já não é nem mesmo "Mattia Pascal" ou "Adriano Melis"; não tem nome, porque se desdobra em cada uma das partes do seu próprio corpo ("um Moscarda com nariz reto ou para, todos os outros, um Moscarda com o nariz torto") e, assim. expressionisticamente, decompõe-se em mil e tantas imagens, conforme a relação em que se põe com os demais. E, numa discursividade ondulante que se desenrola vertiginosamente, até que a "paixão raciocinante" chegue ao climax e o leve ao hospício, esse poliédrico Moscarda encontra, afinal o sentido da existência: "Nenhum nome. Nenhuma recordação, hoje, do nome de ontem; do nome de hoje, amanhã. Se o nome é a coisa; se um nome é, em nós, a conceito de cada coisa posta fora de nós; e sem nome não se tem o conceito (. ) um nome é apenas isto, epígrafe funerária. Convém aos mortos. A quem acabou. Estou vivo e não acabo. A vida não acaba. E nada sabe acerca de nomes, a vida. Esta árvore, sopro trêmulo de folhas novas. Sou esta árvore. Árvore, nuvem; amanhã, livro ou vento; o livro que leio, o vento que bebo. Tudo fora, vagabundo."

Os períodos breves, o discurso "staccato" a respiração cortada numa identificação estranhamente panteísta confirmam a razão e loucura desse personagem, para elas são uma mesma coisa. Não muito diferente é a "lúcida loucura" de "Enrico IV" ainda que o aproximemos da sua fonte artística, que é o "Hamlet" de Shakespeare. Como o Príncipe da Dinamarca, os seus monólogos são povoados de sombra e de incerteza, mas os monólogos daqueles se diri-

(8) - Castris, L. de, Storia di Pirandello, Bari, Laterza, 1962.

(9) - Uno, nessuno, centomila, Firenze, Bemporad, 1926. 
gem à vida, enquanto os deste oscilam entre os seres que o circundam, entre a veracidade destes e o papel que cabe a cada um:

"É preciso perdoá-los! Isto, isto que para mim é a caricatura, evidente e volutária, desta outra mascarada, contínua, de cada minuto, de que somos os palhaços involuntários... - Estou curado, senhores, porque sei perfeitamente, que aqui represento o louco. O pior é para vocês, que, sem saber e sem ver, vivem, agitadamente, a sua loucura!"

Ao fim de tanta elocubração culmina o trabalho discursivo de Pirandello, que a tantos pareceu não poético mas, cuja força dramática procura equacionar os limites da vida e do sonho, da razão e do sentimento num transporte genial para uma arte que não é o espelho da realidade, ao contrário, procura apreendê-la na sua totalidade e que, seja, talvez um aprofundamento de raízes imersas no substrato de uma sociedade incessantemente ameaçada pelo caos. 